\section{EFFECTS OF LOW FREQUENCY ULTRASOUND COMPARE WITH HIGH FREQUENCY ULTRASOUND IN KNEE OSTEOARTHRITIS}

\section{ABSTRACT}

OBJECTIVE

To compare the effectiveness of low and high frequency Ultrasound (US) STUDY DESIGN

tis a pre-post design was used with multiple treatment therapies (A and B). STUDY SETTINGS \& PARTICIPANTS

The study was conducted on the 310 patients. The patients were diagnosed knee OA by the orthopedic doctor and recommended to the Physiotherapy department of North and Clifton Campus of Ziauddin Hospital. In this study 310
patients were divided into two groups. Group A of 155 patients received low
frequency $U$ streatment of 0.01 MHz frequency for 10 min and at the same time Group B of 155 patients received high frequency US treatment of $1 \mathrm{MHz}$ for about 3 min. Both the groups had 6 sessions in 3 weeks.

\section{RESULT}

There was a mean reduction in the pain and disability with difference of low
frequency US and high frequency US pre score and post score treatments of both the groups is $1.2 \pm 0.3$ and $4.1 \pm 1.0$, there was statistically significan difference between the effects of low frequency US and high frequency US in CONCLUSION

There was difference between the effectiveness of low frequency US and high

\section{INTRODUCTION}

Osteoarthritis is by far most common form of arthritis. It is pain and dischility in aing and is the major cause of age-related condition, occuring more frequently in males as compare to females'. Pathologically it is defined as condition of synovial joint characterized by focal loss of hemolding of joint contour2. The knes, hands hips, and and feet include the joints most offen affected by $\mathrm{OA}^{33}$. OA prevalence, effect on health and economics conse quences are expected to increase dramatically during prevalen of $30 \%$ of people have radiographic evidence of OA through only 25-30\% are symptomatic. The main clinica symptoms related by pafients with knee OA include pain. range of motion (ROM), physical activity limitations and muscle weakness ${ }^{4,6}$. Osteoarthritis treatment aim is to mprove physical function, prevent disability, reduce or minimize pain and enhance quality of life'. In Singapore thritis was the fifth leading cause of disability .

One Iranian study concluded that prolonged squatting A. with housewives being of orecter risk of deve kning knee OA than women whose main occupation was outside the home? ${ }^{9}$. Disability is more rapidly reported in he cases of knee $O A^{*}$. In the Netherlands, patients with hip and knee pain, of 55 to 74 years of age, are o severe disability in 43.4 million people as of 2004"'. The rate of reduced employment and lost work contribute to and harect costs of musculoskeletal conditins'. Kelgren and Lawrence also
system for knee OA $\mathrm{A}^{\text {'3. }}$.

Grade 1: doubtful narrowing of joint space and possible steophyte lipping

作 Grade 3: moderate multiple osteophytes, definite narrow ing of joint space, some sclerosis and possible deformity

Grade 4: large osteophyte marked narrowing of joint space, severe sclerosis and definite deformity of bone
contour. Ultrasound (US) is described as micro- massage.

These are essentially the same as sound waves but of higher frequency, such waves that are beyond the skeletal diseases and is also reputed to reduce edema. elive pain increase range of motion and accelerate vibration at a frequency above the sound range but it it frequency of a few megahertz that are typically used in physiotherapy several frequencies range from 0.5 to Phyz. They us and low frequency us They produd $\mathrm{High}$ types of effects, thermal and non thermal. Therm effects are due to the absorption of the sound waves. Non thermal effects are from cavitations, micro streaming modality to generate heat within a body part ${ }^{3}$ The resu mefurvey carried out in Britain in 1985 (ter-Har. Dyson and Oakley, 1985) showed that $20 \%$ of all physiotherapy treatments in NHS department and $54 \%$ of all private physiotherapists were asked to comple questionnaire covering a range of topics including technical details of heir US machine, intensities, caliberation procedure

Lw frequency US has good effects since the early 1990 There has been an interest in the use of low frequency us for the treatment of variety of tissue injures (Bradnock, Law and Roscoe, 1996). Typically this modality operates lower than the usual therapy ranges $1-3 \mathrm{MHz}$.

\section{HYPOTHESIS}

The research hypotheses are as follows; effects in the management of knee OA.

Ha: low and high frequency ultrasound both have

\section{METHODOLOGY}

is a pre-post design study conducted on 310 patients in 2012). The study includes male and female with age range of 40-65 years. All participants were suffering from confirmed diagnosed osteoarthritis of knee joint accordance to the American College of Rheumalology participating into the study, thereafter; the subjects were randomly divided into two groups, Group A and Group B each consisting 155 patients. Both groups received same protocol of treatment, incluading ice pack \{ Preheating the . 1978) $\}^{19}$ and stretching exercises except. Group A received low frequency Us treatment of $0.01 \mathrm{MHz}$
frequency for $10 \mathrm{~min}$ and at the same side Group B received high frequency US treatment of $1 \mathrm{MHz}$ about 3 min. Both groups had six sessions in 3 weeks, Before and after the treatment of both groups we examined pain and disability of patient by different method. Pain intensipre-treatment and post-treatment and disability was examined by a questionnaire in which pre-treatment and post-treatment scores are calculated by adding the numbers of answered oppions. Data was analyzed on the study: patient within age of 40-65years, patient with diagnosed knee osteoarthnitis, patient with pain in knee and Grade 1,2,3 OA of knee ${ }^{13}$. While patients fulfiling following citeria were excluded. patients with inflammaknee any neurological involvement diabetic patient or patient with any cardiac disorder, tumor, malignancy, bone tissue infection, cardiac pace maker and over plastic implantso. Palle car with grade 4 OA

Study Setting

The study is taken in Physiotherapy department of North Narachi Pakistan.

ariable of the Study

The study following variables are being tested: i. Knee pain
ii. Disability

Devi J, labal S. Effects of Low requency Ultrasound compare with Osteoarthritis. Pak. j. rehabil.
. 2012;1(1):9-12.

Sampling Method 
included in the study.

Group A: 155 patients were selected with age range of 40 Group B: 155 patients were selected with age range of

Ethical Consideration

According to ethical consideration patient privacy is most important, patient hygiene factor, Patient therapis relationship
the patient.

\section{Finding and Analysis}

1) It includes the basic statistical information of pre and

post scores of the treatments
2) The box plot shows the normality of data and its

3) The third and final part of the Finding and analysis is based on the independent t-test which
efficient treatment among both groups.

\section{RESULTS}

The descriptive statistics (table 1) provides useful statistics for both groups $A$ and $B$. The tables show the pre and pos is 310 (group $A=155$ and is 310 (group $A=15$, and group $B=155$ ) ranges from the 65 which are further divided on the bases of gender (Male $35.8 \%$ and Female $64.2 \%$ ). The significance of both the treatment is less than 0.05 which means both

Table 1: Comparison of score before and after treatment
\begin{tabular}{|l|c|c|c|c|}
\hline Group & $n$ & $\begin{array}{l}\text { Pre-score } \\
\text { Meant } \pm \text { SD }\end{array}$ & $\begin{array}{l}\text { Post-score } \\
\text { Mean } \pm \text { SD }\end{array}$ & $\begin{array}{l}\text { P- } \\
\text { value }\end{array}$ \\
\hline $\begin{array}{l}\text { Low } \\
\text { frequency } \\
\text { ultrasound }\end{array}$ & 155 & $33.1 \pm 2.3$ & $22.1 \pm 1.5$ & $<0.05$ \\
\hline $\begin{array}{l}\text { High } \\
\text { frequency } \\
\text { ultrasound }\end{array}$ & 155 & $31.8 \pm 1.1$ & $26.2 \pm 2.5$ & $<0.05$ \\
\hline
\end{tabular}

The box plot shows that the high frequency ultrasound treatment has less efficiency in pain management of
osteoarthritis of knee joint as compare to low frequency osteoarthritis of knee
ultrasound treatment.

The data is normally distributed (table 2) and there are no be less than as compare to the range of high frequency be less than as compond treatment.

The Levene's test for equality of variances in the variable are statistically significicant lif the significance variable are statistically significant (if the significance
less than 0.05 we assumed equal variances amongst the group)

The $t$ statistics shows that there is a difference between evel oft-statistics also shows the same result so we reject HO that is low and high frequency ultrasound provides same effects in the management of knee osteoarthrits. high frequency ultrasound both have different effects in

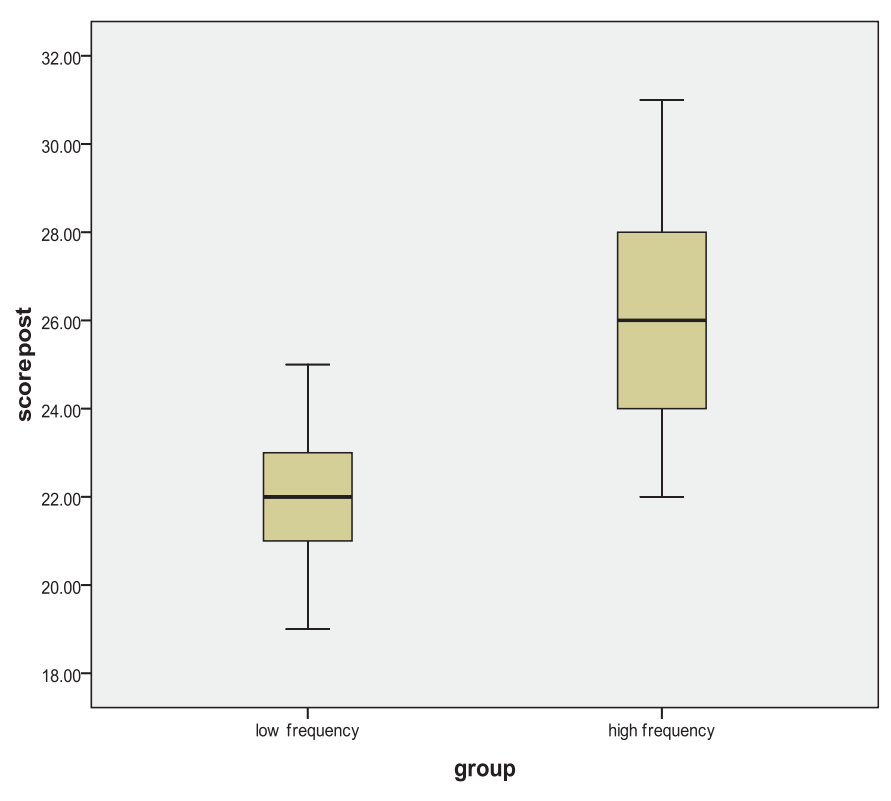

the management of knee osteoarthritis the descriptive statistics also supported our result that there is a difference
between the effectiveness of both the treatments.

Table 2: Individual treatments differences

\begin{tabular}{|c|c|c|c|c|}
\hline & \multicolumn{2}{|c|}{ Levene's } & \multicolumn{2}{|c|}{$t$ test } \\
\hline $\begin{array}{c}\text { Groups } \\
\text { (prea and post } \\
\text { scores) }\end{array}$ & $\mathrm{F}$ & sig & $\mathrm{t}$ & $\begin{array}{l}\text { Sig. (2- } \\
\text { tailed }\end{array}$ \\
\hline $\begin{array}{l}\text { Low and high } \\
\text { frequency US } \\
\text { pre scores }\end{array}$ & 4.204 & 0.041 & 5.276 & 0 \\
\hline $\begin{array}{l}\text { Low and high } \\
\text { frequency US } \\
\text { post scores }\end{array}$ & 26.092 & 0 & -17.01 & 0 \\
\hline
\end{tabular}

We know that the low frequency ultrasound is more
effective in the treatment of knee osteoarthritis. On the basis of descriptive analysis we can say that the low frequency ultrasound treatment is more effective as
compare to high frequency ultrasound treatment in pain management of knee osteoarthritis. Low frequency Ultrasound shows greater depth of penetration but lower spatial resolution it is mostly used for deeper structures

\section{DISCUSSION}

Several authors researched the effectiveness of
therapeutic US and there controversial results in US inerapeutic US and there controversial results in US
efficiency $y^{20.22223}$. The effectiveness of US is still inconclusive so, in this study we investigate the effectiveness of US in knee $\mathrm{OA}$. In this study 310 patients were divided into two patients) respectively, Ancluding male and fromale $B$ with age range of 40-65 years Both groups received same protocol of treatment, including ice pack and stretching exercises except. Group A of 155 patients received low 10 min and at the same side Group B of 155 patients received high frequency ultrasound treatment of $1 \mathrm{MHz}$ about 3 min. Both groups had six sessions in 3 weeks. Before and after the treatment of both groups we examPain intensity was examined by a visual analogue scale
(VAS) both pre-treatment and post-treatment and disabilty was examined by a questionnaire in which pre-treament and post-rreatment scores are calculated.

The descriptive statistics compares pre and post treatment scores which show the significance level of
both the treatment is less than 0.05 which means both the treatments are effective. The box plot shows the data which we conducted have no outlers, we have conducted independent sample t-test in which on bases of F statistics and its significance level the groups have equal variances. The further ancilysis is based on this ultrasound both have different effects in the manage ment of osteoarthritis. Other studies show that ultrasound therapy is reported in relieving pain and improving in that us therapy is unsafe. In three trials no side effects were reported both in the control group and in the

\section{CONCLUSION}

We conclude that low and high frequency ultrasound both have different effects in the management of OA (on bases of $95 \%$ confidence intervall. In accordance to these resuls we cide ultrasound, the low frequency ultrasound is found to be more effective to the patients.

\section{ACKNOWLEDGEMENTS}

We are really thankful to Almighty Allah for granting me
wisdom and understanding to value through learning wisdom
process.

We also thankful to administrative and supporting staffs of
Ziauddin Medical University for relevant information and supporting me throughout the course of my research.

Special thanks: To Ms. Syeda Nida Imran and Mr. Syed Ahmed Raza Kazmi for all their help

\section{REFERENCE}

[1] Solomon DH, Bates DW, Panush RS, Katz Jn. Costs, Outcomes, and Patient Satisfaction by Provider Type for Patients with Rheumatic and Musculoskele-
tal Conditions: A Critical Review of the Literature and Proposed Methodologic Standards. Ann Inter

[2] College NR, Walker BR \& Ralston SH Davidson's Principles and Practice of Medicine. 21 st edition. China: Elsevier Science Limited, 2010. 10835

[3] Osiri $M$, Welch $V$, Brosseau L, Shea B, mcgowan ugwell $P$, wells $G$. Transcutaneous Electrical Nerre
Stimulation for Knee Osteoarthritis. Cochran Database of Systematic Reviews 2000; (4):CD002823.

4] Leslie M. Knee Osteoarthritis Management

[5] Oliveria SA, Felson DT, Rued Jl, et al. Incidence of
symptomatic hand, hip and knee osteoarthritis symptomatic hand, hip and knee osteoarthritis
among patients in a health maintenance among patients in a health maintenance
organization. Arthritis Rheum 1995; 38(8):1134-41.

[6] Bennell KL, Hinman RS, Metcalf BR, Buchbinder R, mcconnell J, Mccoll G. et al. Efficacy of Physiotherapy Management of knee joint Osteoarthritis: A A
Randomised, Double Blind, Placebo Controlled Trial. Ann Rheum Dis 2005;64(6):906-12.
[7] Felson DT, Zhang Y, Hannan MT, et al. The Incidence and Natural History of knee Osteoarthritis in the
Elderly. The Framingham Osteoarthritis Study. Elderly. The Framingham Osteoarthritis Sludy.
Arthritis Rheum 1995;38(10):1500-5.

Shua HP, Singapore's burden of disease and injury, Dahaghin S, Tehrani-baninashemi SA, Gaezi ST, Jamshidi AR, Davatchi F. Squatting, sitting on the
floor or cycling: are life-long daily activities risk floor or cycling: are life-long daily activities risk
factors for clinical knee osteoarthritis. Arthritis Rheum

[10] Huang MH, Lin YS, Lee CL, et al. Use of Ultrasound to Increase Effectiveness of Isokinetic Exercise for knee
Osteoarthritis. Arch Phys Med Rehab Osteoarthritis. Ar. Arch
2005;86(8):1545-51.

[11] Hopman-Rock M, de Bock GH, Bijlsma JW et al. The pattern of health care utilization of elderly people with arthritic pain in the hip or knee. Int I Qual
Health Care 1997:9.129-137

[12] Yelin E. Cost of musculoskeletal diseases: impact of work disability and functional decline. J Rheumatol
suppl. 2003:68:8-11.

[13] Kellgren JH, Lawrence JS, J, et al. Radiological assessment of osteo- arthrosis. Ann Rheum Dis 1957

(14] Low J. Electrotherapy explained principle and practice. 3rd ed. Bostan: Butterworth heinemann;

15] Vander DA, Vander GJ, Vanden SG. Ultrasound Therapy for Musculoskeletal Disorder: a systemic
review. 1999:81:277-71.

[16] Steven, MO, Constantin CC, Len S, Robert Carlisle. Ultrasound-Enhanced Drug Delivery for Cancer. 17] Kitchen S, Young $S$ Electrotherapy. 11 th ed. Elsevier

Science Limited; 2002.211-4
[18] Hochbery MC, Atlam RD, Brandth KD, et al. Guide Part2. Osteoarthritis of knee American College of Rheumatology. Arthritis Rheum 1995;38(11):1541-6. 19] Belanger AY, \& Therapeutic Electrophysical Agents. $2009.405-6$

[20] Tascioglu F, Kuzgun S, Armagan O, Ogutlerget A Short Term Effectivness of Ultrasound Therapy in
Knee Osteoarthritis. J Int Med Res D. $1233-42$.

Anita YN, Doherty M. What of Guide Line:
arthritis. Int Journal Rhem Dis 2011:14 (2): $136-44$.

[22] Falconer J, Hayes KY. Change RW. Effects of
Ultrasound on Mobility in Osteourthritis of the Knee.

Hotpack, Shortwave Diathermy Ultrasound and TENS on Isokinetic Strength, Pain and Functional status of Women with Osteoarthritic Knees: A Single
Blind, Randomized Controlled Trial. Am J Phys Med Rehabil 2008:87:443-51.

[24] Ozgonenel L, Aytekin E, Durmusoglu G. A Double
Blind Trial of Clinical Effects of Therapeutic Blind Trial of Clinical Effects of Therapeutic
Ultrasound in knee Osteoarthritis. Ultrasound Med Bio 2009:35(1):44-9.

Kozanoglu E, Basaran S, Guzel R, Guleruysalf. Short
Term Efficancy of ibuprofen Phonophoresis versus Con 